\title{
Hydrogen, oxygen and carbon isotopes of carbonic waters in the Daurian hydromineral oblast' (Transbaikalia, Russia)
}

\author{
Leonid V. Zamana ${ }^{1, *}$ \\ ${ }^{1}$ Institute of Natural Resources, Ecology and Cryology SB RAS, 672014 Chita, Russia
}

\begin{abstract}
The results of isotopic analyzes of about 40 samples of carbonic waters are presented, dependencies of isotopic relationships between themselves and with bicarbonate were analyzed, the causes of these dependencies are explained, conclusions on the genesis of $\mathrm{CO}_{2}$ are made.
\end{abstract}

\section{Introduction}

The territory of the Daurian hydromineral oblast' (DHO), which covers mainly the southern part of Eastern Transbaikalia, is second only to the region of the Greater Caucasus in the number of carbonic waters manifestations. After the first published information appeared in the 1780 s, by the middle of the last century, about 280 carbic waters springs were recorded. The studies were practically limited to the determination of the chemical composition, and isotopic studies were carried out solitary. Studies conducted by author in recent years have allowed us to obtain statistically reliable estimates for the $\mathrm{O}, \mathrm{H}$, and $\mathrm{C}$ isotopes of carbonic waters and their interrelationships (presented in this report).

\section{Study area and methods}

The area researched is represented mainly by the middle-height mountains, with alternation of mountain ranges stretched in the northeast direction and intermountain depressions separating them. The ridges are composed mainly of Paleozoic granites, less of Mesozoic age, paleozoic metamorphic rocks (which include carbonate rocks), and are limited in their development. The depressions are made of Mesozoic effusive-sedimentary rocks, with a predominance of terrigenous sediments in several of the coal-bearing depressions. The thickness of Cenozoic loose sediments covering the Mesozoic rocks do not exceed $100 \mathrm{~m}$, and are usually several tens of meters. Cenozoic volcanism was not manifested within the boundaries of the area tested for carbonic waters. Carbonic water sources are common in geological structures of both types (mountain uplifts and intermountain depressions) and, are confined to local or regional faults.

The components of the chemical composition of water were determined in the laboratory of the Institute of Natural Resources, Ecology and Cryology of the Siberian

* Corresponding author: 1.v.zamana@ mail.ru 
Branch of the Russian Academy of Sciences (Chita). Isotopic analysis of water and carbonates were performed in the laboratory of stable isotopes of the Geological Institute of the Far East Branch of the Russian Academy of Sciences (Vladivostok). Water samples for analysis were filtered through paper filters with a pore diameter of 2-3 $\mu \mathrm{m}$ to remove mechanical suspensions. Samples of carbonates for isotope analysis were obtained by precipitation with calcium chloride. The $\mathrm{CO}_{2}$ emitted by the method of carbonates decomposition in $100 \%$ phosphoric acid under vacuum conditions at a temperature of $95^{\circ} \mathrm{C}$ was purified by the method of cryogenic separation. Isotopic ratios of $\mathrm{H}$ and $\mathrm{O}$ of water and carbonates are presented to the SMOW standard, and carbon is presented according to the PDB standard. The reproducibility of the analysis results $(1 \sigma)$ for water were oxygen \pm 0.15 and hydrogen \pm 1.2 , and for carbon and oxygen of carbonates $\pm 0.1 \%$.

\section{Results and discussion}

Isotopic analyzes were performed on most of the nearly 50 manifestations of carbonic waters tested. The chemical composition of them, with a few exceptions, was alkaline earth bicarbonate with a variable ratio of $\mathrm{Ca}$ and $\mathrm{Mg}$. Only in water with maximum TDS was sodium the main cation [1]. The isotope composition of water oxygen (Table 1) at its extreme values, was lighter than the carbonic waters of the Greater Caucasus, in which $\delta^{18} \mathrm{O}$ varied from -2.5 to -14.914 [2] and Sikhote-Alin with $\delta^{18} \mathrm{O}$ from -11.83 to $-14.59 \%$ [3]. The picture is similar for hydrogen, the $\delta \mathrm{D}$ values in the compared regions are set in the intervals of $-56.2 \ldots-109.8$ and $-79.1 \ldots-105.0$ in the Greater Caucases and Sikhote-Alin, respectively. Smaller $\delta^{18} \mathrm{O}$ values showed water from the Tersinskoe deposits in Kuzbass (up to -18.0 [4]) and Mukhen in the Khabarovsk Krai (-25.2 in one of the samples [5]).

Table 1. Statistical characteristics of carbonic-acid components, TDS and isotope ratios of water and dissolved carbonates of carbonic waters DHO

\begin{tabular}{|l|l|l|l|l|c|}
\hline Parameter & $\mathrm{n}$ & average & min. & max. & standard deviation \\
\hline $\mathrm{CO}_{2}, \mathrm{mg} / \mathrm{l}$ & 43 & 1965.0 & 234.0 & 4351.0 & 899.1 \\
\hline $\mathrm{HCO}_{3}^{-}, \mathrm{mg} / \mathrm{l}$ & 43 & 1190.4 & 113.0 & 5887.0 & 938.0 \\
\hline $\mathrm{TDS}, \mathrm{mg} / \mathrm{l}$ & 43 & 1600.7 & 167.0 & 7918.0 & 1250.8 \\
\hline$\delta \mathrm{D}_{\mathrm{H} 2 \mathrm{O}}, \% 0$ & 36 & -100.75 & -116.60 & -83.10 & 6.70 \\
\hline$\delta^{18} \mathrm{O}_{\mathrm{H} 2 \mathrm{O}}, \% 0$ & 36 & -13.50 & -15.40 & -10.40 & 1.15 \\
\hline$\delta^{18} \mathrm{O}_{\mathrm{HCO}-}, \% 0$ & 42 & 14.46 & 8.20 & 18.80 & 2.42 \\
\hline$\delta^{13} \mathrm{C}_{\mathrm{HCO}-}, \% 0$ & 42 & -3.54 & -10.70 & 3.90 & 3.75 \\
\hline
\end{tabular}

Note. $\mathrm{n}$ - number of samples.

As can be seen from fig. 1, the trend line has a smaller angle of inclination as compared to the Global Meteoric Water Line (GLMW), which according to H. Craig [6] is described by the equation $\delta \mathrm{D}=8 \delta^{18} \mathrm{O}+10$. The coefficient value at $\delta^{18} \mathrm{O}$ (the $x$ value in the equation on the graph) less than a value of 8 has so-called the "evaporation line" [7], which is characteristic of the waters of evaporating lakes. There are no grounds for explaining carbonic waters weighting due to evaporation. The main role in the weighting of carbonic waters is played by the interaction of water with the host rocks through the formation of secondary clay minerals, in which it is possible to enrich water at ${ }^{18} \mathrm{O}$ by a maximum of 27 $\%$ [8]. On the graph, the points on the abscissa axis are shifted to the right, which leads to a decrease in the slope of the line. When interacting with carbon dioxide through the reaction $\mathrm{H}_{2} \mathrm{O}+\mathrm{CO}_{2}=\mathrm{H}_{2} \mathrm{CO}_{3}$, water, on the contrary, loses the isotope ${ }^{18} \mathrm{O}$ and becomes oxygen more easily, as was shown by the therms of Larderello in Italy [8]. This case could explain the position of the points above the GLMW. 
Carbon, by definition of $\delta^{13} \mathrm{C}$ in precipitated carbonates (taking into account fractionation coefficients between $\mathrm{CO}_{2}, \mathrm{HCO}_{3}{ }^{-}$and $\mathrm{CO}_{3}{ }^{2-}$ ), is lighter than in the case of $\mathrm{CO}_{2}$ formation during thermometamorphism of carbonate rocks, and in many cases is less than the values of $\delta^{13} \mathrm{C}$ at which its intake is associated with mantle sources $(-4 \ldots-8 \%$ [9]). According to the geological and structural conditions of the location of carbonic water manifestations, the mantle genesis of $\mathrm{CO}_{2}$ is unlikely. We are inclined to its crustal sources, at low $\delta^{13} \mathrm{C}$ - with the participation of methanogenesis.

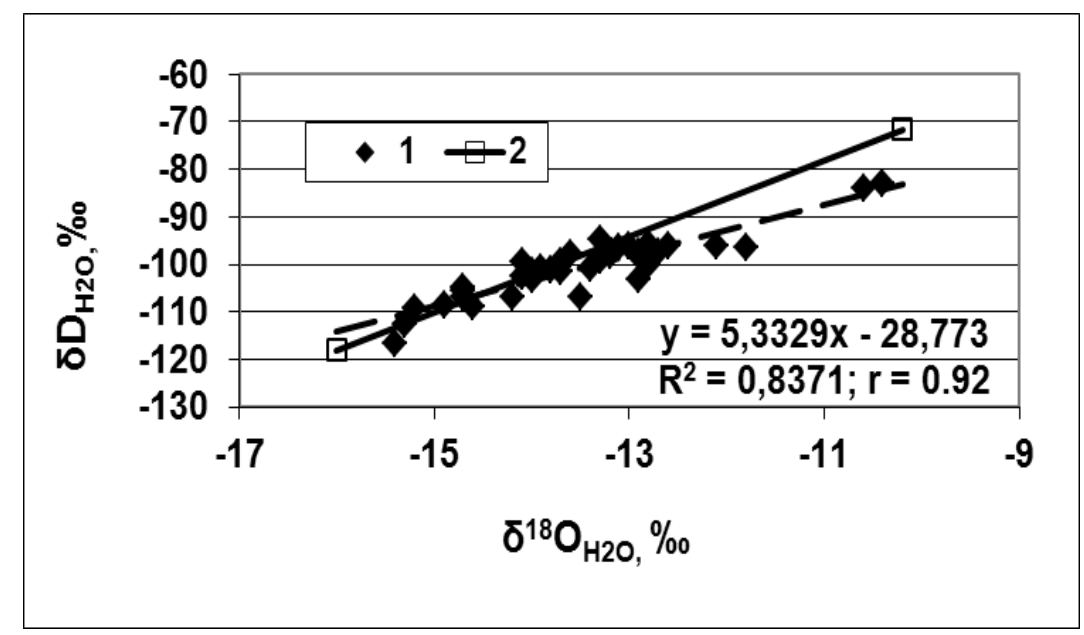

Fig. 1. The ratio between water isotopes in the carbonic waters of DHO. Legend: 1 - point of carbonic waters, 2 - GLMW by [6].

From fig. 1 we can conclude that carbonate components in DHO carbonic waters, due to the right-sided displacement of points along the $\delta^{18} \mathrm{O}$ axis relative to GLMW, are predominantly petrogenic, and are formed due to carbon dioxide leaching of host rocks, during which oxygen isotopes are redistributed in the gas - water - host rock - secondary minerals system. Only when the points are located above this line does the formation of carbonates by the reaction of $\mathrm{CO}_{2}$ with water make a more noticeable contribution to the formation of the isotopic characteristics of the water itself and largely determine them.

The dependencies represented in the Fig. 2, show that as concentrations of bicarbonate increase, carbon in the bicarbonate becomes heavier (left side of the figure). For water isotopes, the trend is the opposite (right side), although the correlation coefficients did not reach a significant level in neither in oxygen nor in hydrogen (Table 2). The latter can be explained by the heterogeneity of the hydrogeochemical systems of the waters under consideration, and the different directions of the processes forming these systems with respect to isotopic separation.

The statistically significant inverse relationship between the $\mathrm{C}$ isotopic characteristics of carbonates, and $\mathrm{O}$ and $\mathrm{H}$ of water (Table 2, Fig. 4) at first glance contradicts Figure 3. But if we consider the relationship as a reflection of the influence of $\delta^{13} \mathrm{C}$ on the isotopic composition of water after the formation of bicarbonate, it is natural. As a result of the water becomes lighter in both chemical elements, as noted above when analyzing other dependencies, their heavier isotopes react. The heavier the carbon, the greater the number of heavy isotopes $\mathrm{O}$ and $\mathrm{H}$ goes into $\mathrm{HCO}_{3}{ }^{-}$, although the correlation coefficient between $\delta^{13} \mathrm{C}_{\mathrm{HCO} 3-}$ and $\delta^{18} \mathrm{O}_{\mathrm{HCO} 3-}$ (see Table 2) is not visible. 


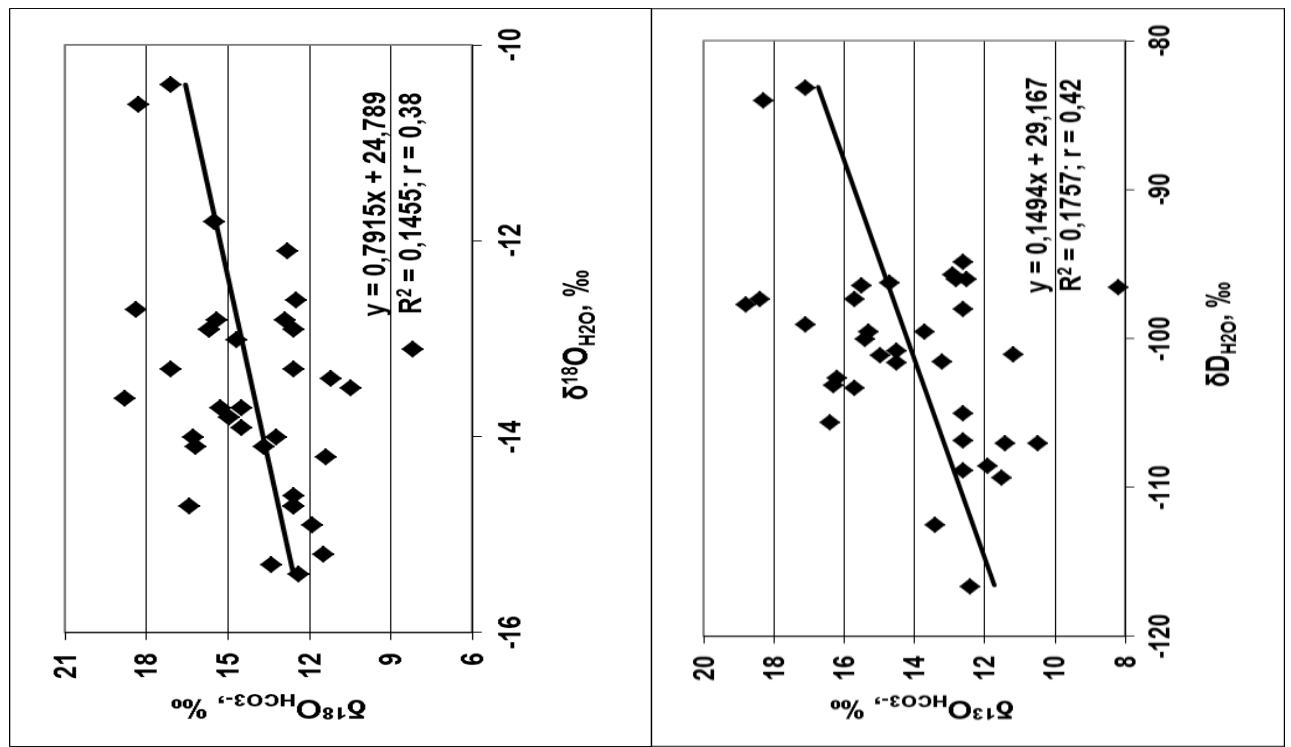

Fig. 2. The relationship between the isotope ratios of oxygen and hydrogen of water and oxygen of bicarbonate in carbonic waters of DHO.

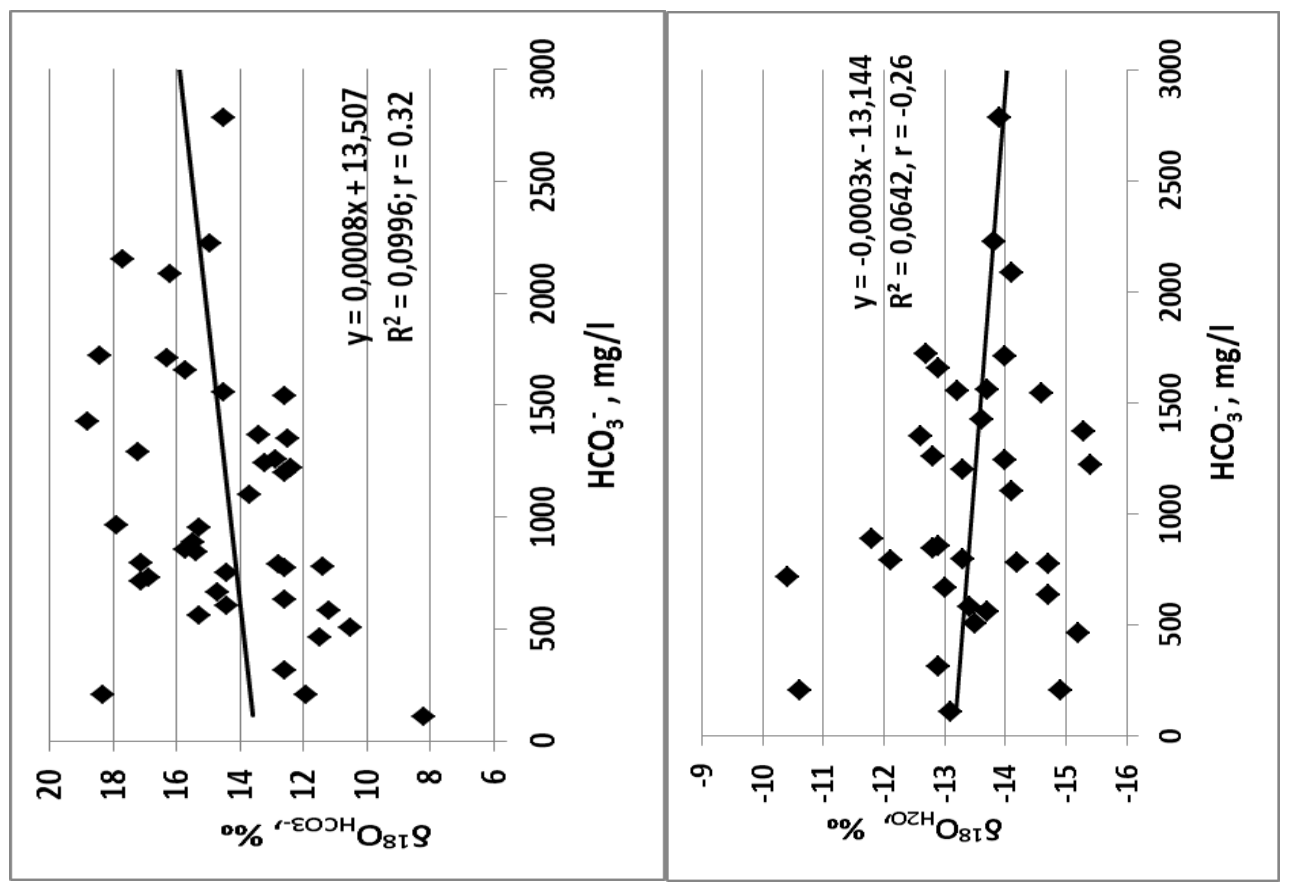

Fig. 3. The relationship between the concentration of bicarbonate and the isotopic ratios of oxygen in it and in the water of carbonic waters of DHO. 
Table 2. The coefficients of determination $\mathrm{R}^{2}$ (above the line) and the correlation $\mathrm{r}$ (below the line) between the isotopic ratios of water and dissolved carbonates

\begin{tabular}{|l|l|l|l|l|l|l|}
\hline & $\delta \mathrm{D}_{\mathrm{H} 2 \mathrm{O}}$ & $\delta^{18} \mathrm{O}_{\mathrm{H} 2 \mathrm{O}}$ & $\delta^{18} \mathrm{O}_{\mathrm{HCO} 3-}$ & $\delta^{13} \mathrm{C}_{\mathrm{HCO} 3-}$ & $\mathrm{HCO}_{3}{ }^{-}$ & $\mathrm{CO}_{2}$ \\
\hline$\delta \mathrm{D}_{\mathrm{H} 2 \mathrm{O}}$ & & 0.8371 & 0.1757 & 0.1025 & 0.0332 & 0.0062 \\
\hline$\delta^{18} \mathrm{O}_{\mathrm{H} 2 \mathrm{O}}$ & $\mathbf{0 . 9 1 5}$ & & 0.1455 & 0.12 & 0.0642 & 0.0169 \\
\hline$\delta^{18} \mathrm{O}_{\mathrm{HCO} 3-}$ & $\mathbf{0 . 4 1 9}$ & $\mathbf{0 . 3 8 1}$ & & 0.006 & 0.0996 & 0.0377 \\
\hline$\delta^{13} \mathrm{C}_{\mathrm{HCO} 3-}$ & $-\mathbf{0 . 3 2}$ & $-\mathbf{0 . 3 4 7}$ & 0.078 & & 0.0554 & 0.0259 \\
\hline $\mathrm{HCO}_{3}{ }^{-}$ & -0.182 & -0.253 & $\mathbf{0 . 3 1 6}$ & 0.235 & & 0.1402 \\
\hline $\mathrm{CO}_{2}$ & -0.079 & -0.13 & -0.198 & -0.161 & $\mathbf{0 . 3 7 3}$ & \\
\hline
\end{tabular}

Note. The correlation coefficients that are significant by the Student's criterion for security $\mathrm{P}>0.95$ are highlighted in bold.

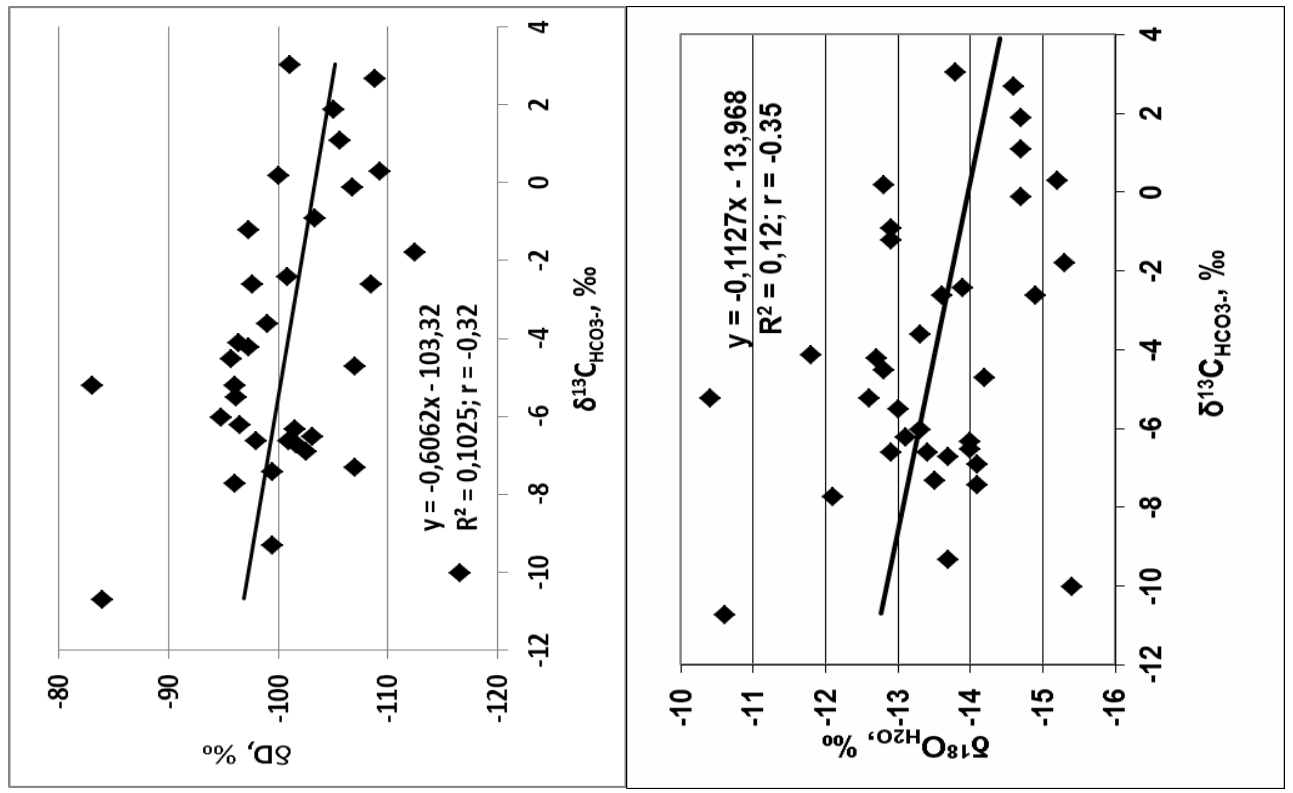

Fig. 4. The relationship between carbon isotope ratios of bicarbonates and oxygen and hydrogen of water in carbonic waters of DHO.

\section{Conclusions}

According to the isotope data obtained, the genesis of water of the carbonic waters considered, as well as the territories cited in the references, is infiltration. The carbon isotope composition did not show participation in the genesis of $\mathrm{CO}_{2}$ by the processes of thermometamorphism of carbonate rocks, and the geological and structural conditions of the territory practically exclude mantle input. Hence, the $\mathrm{CO}_{2}$ in the carbonic waters of this region is most likely crustal, despite the fact that in many cases the values of $\delta^{13} \mathrm{C}$ correspond to mantle sources.

This work was prepared under the project IX.137.1.2 "Geochemistry of rare and rare-earth elements in natural and geotechnogenic landscapes and hydrogeochemical systems" with the support of the grant of RFBR No. 14-05-98015r_sibir_a on the topic "Geochemistry and the formation of carbonic waters of the Daurian hydromineral oblast'". 


\section{References}

1. L.V. Zamana, Voprosy kurortologii, fizioterapii i lechebnoy fizicheskoy kul'tury 95, 69-74 (2018) (In Russian)

2. V.Yu. Lavrushin, Subsurface fluids of the Greater Caucasus and its surrounding. (GEOS, Moscow, 2012) (In Russian)

3. O.V. Chudaev, Composition and origin of the recent hydrothermal systems of the Far East Russia (Dalnauka, Vladivostok, 2003) (In Russian)

4. N.A. Kharitonova, G.A. Chelnokov, S.L. Shvartsev, O.E Lepokurova, Dokl. Earth Sci. 475 953-957 (2017)

5. Y.G. Kopylova, O.E. Lepokurova, O.G. Tokarenko, S.L. Shvartsev, Dokl. Earth Sci. 436, 284-289 (2011)

6. H. Craig, Science 133 1702-1703 (1961)

7. A.K. Henderson, B.N. Shuman, Hydrol. Processes 24 3894-3906 (2010)

8. V.I. Ferronsky, V.A. Polyakov, Isotopes of the Earth's hydrosphere. (Scientific World, Moscow, 2009) (In Russian)

9. M. Javoy, F. Pineau, H. Delorme, Chem. Geol. 57 41-62 (1986) 